\title{
Do conferences have a future?
}

\section{Niek Van Dijk}

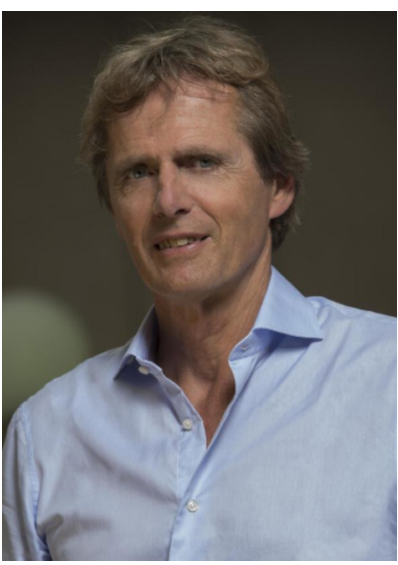

It was December 2019 and it was not far from Wuhan. We organised with Professor Shiyi Chen and Dr Hu a 2-day cadaver workshop for 60 Chinese and 60 international delegates. Those 120 attendees packed into a small but cosy conference room and crowded around the screens during the hands-on sessions so that they would not miss any detail. The severe acute respiratory syndrome COVID-19 virus was already knocking on our door, but at that moment it was unknown to all of us and unknown to the world. And yes: any one of us could have caught it and easily spread it and been patient zero on all continents. This cadaver workshop was my last inperson meeting. Two years have passed and the virus is still dictating our calendar. For the second year in a row, there has not been a gathering of the orthopaedic community at the American Academy of Orthopaedic Surgeons, and now also ISAKOS had to decide to go virtual with their 2021 Cape Town meeting. It will still be great, but different. To a certain extent, it also affects the Journal of ISAKOS (JISAKOS).

Our biannual ISAKOS Congress is an important source of information. It disseminates a wide range of knowledge to the orthopaedic community at the same rate as other prominent orthopaedic meetings, but on a larger international scale. ${ }^{1}$ The high mean impact factor for the publications generated from a podium presentation at an ISAKOS Congress reflects the high volume of publications in prominent high-impact orthopaedic journals such as JISAKOS. We find it important to share this information with our readers and

Correspondence to Professor C Niek Van Dijk, Department of Orthopaedic Surgery, University of Amsterdam, Amsterdam UMC, Amsterdam, The Netherlands; C.NiekvanDijk@JISAKOS.com not just the congress proceedings. We encourage the highlight speakers, award winners and other speakers to publish in our journal. The meeting thus is an essential incubator for potential papers that can be submitted or invited to be submitted to the journal. And a lot of this soliciting is done during face-to-face interaction with the presenters at the meeting.

\section{FUTURE OF CONFERENCES}

Now celebrating its 25 th anniversary, how does the future look for ISAKOS biannual conferences? Will the 2023 meeting in Boston still be virtual, hybrid or inperson?

The present world does bear the seeds of permanent changes in the structure of educational, training and meeting activities. The COVID-19 pandemic has changed our continuous medical education from one moment to the other. Nearly all conferences have been cancelled or postponed. Webinars, virtual learning and virtual conferencing have taken over the exchange of knowledge and learning. Technology develops extremely fast, but can all this learning be replaced just by virtual training? Webinars and virtual training will most probably remain in the future, but to what extent? Hospital administrations surely favour maintaining the virtual training because of the saving in costs and time away from the hospital of their orthopaedic surgeons and healthcare providers. Likewise, the industry saves money when they do not have to sponsor these congress visits, or pack, ship and staff the inperson exhibits that fill meeting halls. Patient organisations and insurance companies will like to keep things virtual. The price for continuous medical education, in the end, is paid by tax money/patients and insurance companies. Politicians and green organisations will like it because of less travelling and thus less pollution. Does this mean we will remain completely virtual? I think not!

Let's first consider the advantages of inperson meetings.

\section{PROS FOR INPERSON MEETINGS}

When you attend a live conference, you spend days away from your practice, so your focus is directed towards this event. You allot your days specifically for this. You prepare yourself, you arrange your schedule to accommodate for these days away from your daily routine. You need to set yourself to register and find yourself in a place away from your everyday environment. A conference is something you look forward to; it brings inspiration and provides you with fresh ideas and positive energy. An important part of any orthopaedic conference is the industry exhibition, where we may find new tools and information that feed us with new ideas.

And there are other socioeconomic and psychological factors that I believe will drive the return to an entire conference and meeting calendar once the COVID-19 pandemic is history. Just to mention a few:

Meeting face to face provides both sides with verbal and non-verbal communication channels, which allow for better interpersonal interaction. ${ }^{2}$ A live meeting offers the possibility of backstage conversations and informal meetings with other participants. In my experience and hearing that of my colleagues, some of the most meaningful educational opportunities occur during impromptu hallway conversations or discussions with other faculty and attendees at a restaurant over a meal or a coffee.

Another issue is the attendance. Once you are in the conference room, it is less easy to exit from the event. For an online meeting, it is difficult to measure and quantify the level of actual involvement.

It is likely that the actual involvement in online educational activities is reduced due to a lower barrier to entry into that activity. Nothing of value is free. And all that is one click away also only requires one click to leave.

Due to the lack of non-verbal channels, it takes more energy to grasp the message online. It is like the difference between drinking through a straw and without a straw :-).

This has led to what is now known as 'digital fatigue'. It has to do with the focus of our attention and concentration of our learning. Webinars and video conferencing ask for much more effort and energy from our brains.

When you dedicate time and physically travel to get to an environment where you can only listen, study, learn and exchange with your colleagues, this means the intensity and focus of your learning are high. When you are in front of a screen, it is not the same; it is not even half, maybe $20 \%$. It is easy to be distracted and not just by looking at all these little backgrounds with distracting interiors, smacking dogs, curious toddlers or all the other things that happen in those houses. But you are also distracted by your own environment: you make yourself a cup of coffee, you receive a WhatsApp, your partner asks a question, you are distracted by the doorbell or by your children, or you might just answer the mails that you receive... why should you not take the opportunity to answer them straight away, since you are in front of a screen anyway. 
And what about this match of your favourite team, which by coincidence happens to be transmitted live at the same time as the meeting. You might as well view it on a second screen: you just mute yourself. And yes, there is an emergency surgery that a colleague would have taken over if you had been out of town for this conference, but you might as well do it yourself since you are still present. We all can fill in the excuses to switch the focus of our attention.

Interaction during intermissions at a live conference provides positive energy; you recharge yourself. When you are in front of the screen, you do not have this possibility to recharge. Whatever entertainment providers of digital conferences are trying to invent, they will never replace the social part/element through the screen. Chats, virtual coffee breaks, virtual wine partiesthey are not the same. It is the social interaction that matters and also the focus of attention. During conferences, you connect with your peers and with your colleagues. Networking is important. New ideas are born by discussions with colleagues during the intermissions. ${ }^{3}$

It is the conference that brings colleagues to life as a group at all. These are the places where the scientific community is built in the literal sense of the word.

For me, there is another critical structural aspect of conferences and the function they have in building the scientific community. It is the fact that people are all present at the same keynotes, feeling the same enthusiasm when there is a new discovery, method, theory, etc is presented and then discussed by everyone present.

Conferences have effects at the level of the individual but certainly also at higher levels of scientific groups, networks and even scientific communities.

Other advantages of live conferences include face-to-face discussion of career opportunities for young researchers and the social informal knowledge circuit that is important for science (job opportunities, access to funds, and others). These also provide opportunities to make new contacts (equalising the effect that young researchers can more easily get in touch with the stars in the field) to network. Sometimes this leads to new collaborative projects between individual researchers or between research groups, which in turn can have an effect on science as a whole. Live conferences also provide a physical and formative experience for beginning researchers to address a live room on their research. ${ }^{4}$

Some experts have emphasised the learning process is much better and more in depth if it is reciprocal and interactive instead of a virtual one-way traffic. ${ }^{5}$

\section{DO WHAT YOU LOVE}

Do what you love. Sometimes these virtual meetings are quite the opposite: it is an undesired break from your daily activities, and while you sit in front of a screen your attention tends to be distracted. And then there are the challenges of providing virtual live presentations to attendees in different time zones, which means that inevitably some are forced to $\log$ in after midnight or at times that are less desirable or less advantageous for optimal focus and processing of information. Virtual learning and webinars lack oneto-one interaction. The personal interaction with teachers, presenters and fellow congress participants cannot be replaced by a webinar. But how important is this?

As a presenter, you might find it much more difficult to orient yourself because you lack direct feedback. You miss the body language of your audience and the eye contact. You miss the talk with your colleague presenters during the intermissions. The questions are asked after the presentation by participants who queue up or whom you meet later on in the corridors. In a webinar, you do not see your audience, you talk to yourself, and when you are finished it leaves one with an empty feeling.

It is, however, not difficult to realise that we will need to get used to digital life. And we already have. And we all appreciate some of the benefits of access to information (Google Search!, online journals) and communication (email) that digital technology has also brought. It will be a question of how to fit it in rather than an overall replacement.

\section{PROS FOR VIRTUAL}

Changing the formula of meetings to remote and online brings benefits such as lower costs and less time involvement of participation in events: the summit is just 'one click away'. During a virtual meeting, there is a lower barrier to communicate with opinion leaders related to the greater anonymity of participants and a lower barrier to enter a question and answer (Q\&A) session. People who do not or cannot tune in for it when it is happening live can still watch and listen to the presentations later when they have the time and opportunity. This is a convenience that not all live conferences have. Many capture live events digitally and then post them online after the conference for those who could not attend. However, these will not benefit from Q\&A from the viewer, which is a great benefit.

ISAKOS is undoubtedly embracing the digital formats with their webinar series, which have had excellent participation and attendance from audiences, especially regionally. It does provide an excellent opportunity for more people to join due to the convenience of not having to travel and spend time away from work and is very beneficial for those who lack the resources or ability to travel long distances. Virtual events are also a bit of an 'equalizer' for those in developing countries. It gives them access to high-level education and faculty that they might not get regionally.

Another significant benefit of virtual, which is especially relevant in ISAKOS' case, is that being a global organisation that often provides content that contains perspectives from multiple experts in different countries or regions of the world, the virtual webinar or session offers a much easier way to bring diverse perspectives together more frequently and without the time and expense burden of travel.

Finally, they provide the possibility of 'packing' more educational and scientific activities in a shorter time, as well as much greater ease in direct transmission of documents, analysis and studies.

And in fact, we should all be thankful that we have these possibilities of digital teaching, meetings, communication and conferencing.

Imagine that the pandemic and lockdowns had taken place in the 1970 s or 1980s. Education would have come to a standstill for almost 2 years!

\section{TO CONCLUDE}

Scientific meetings with their unseen interplay of emotions are something which we all look forward to. A conference brings inspiration and provides us with fresh ideas and positive energy. And although it is easier to relax and concentrate and learn when we are physically surrounded by our colleagues (and can sense them there), we can certainly appreciate and take advantage of a virtual meeting. Future education models will probably be hybrid and combine the best of both worlds.For the upcoming Cape Town meeting, Volker Musahl and the scientific committee have composed a fantastic programme. We can be sure that ISAKOS, with the creativity and inspiration of so many, will create an unforgettable experience for all those who will attend.

As for the presenters at our Cape Town conference, please do it without this unseen interplay of emotions and consider my request to submit your manuscripts to JISAKOS. Digitally, of course!

Funding The authors have not declared a specific grant for this research from any funding agency in the public, commercial or not-for-profit sectors.

Competing interests None declared.

Patient consent for publication Not required. 
Provenance and peer review Commissioned; internally peer reviewed.

\section{(อ)}

\section{OPEN ACCESS}

Open access This is an open access article distributed in accordance with the Creative Commons Attribution Non Commercial (CC BY-NC 4.0) license, which permits others to distribute, remix, adapt, build upon this work non-commercially, and license their derivative works on different terms, provided the original work is properly cited, an indication of whether changes were made, and the use is non-commercial. See: http:// creativecommons.org/licenses/by-nc/4.0/.

(c) International Society of Arthroscopy, Knee Surgery and Orthopaedic Sports Medicine 2021. Re-use permitted under CC BY-NC. No commercial re-use. Published by BMJ.

\section{D) Check for updates}

To cite Van Dijk CN. J ISAKOS 2021;6:319-321.

J ISAKOS 2021;6:319-321.

doi:10.1136/jisakos-2021-000733

\section{REFERENCES}

1 van Dijk CN. Flying high. J ISAKOS 2020;5:61-2.

2 Zierath JR. Building bridges through scientific conferences. Cell 2016;167:1155-8.

3 Hauss K. What are the social and scientific benefits of participating at academic conferences? insights from a survey among doctoral students and postdocs in Germany. Res Eval 2021;30:1-12.

4 Oester S, Cigliano JA, Hind-Ozan EJ, et al. Why conferences Matter-An illustration from the International marine conservation Congress. Front Mar Sci 2017;4.

5 Schreurs B, Cornelissen F, De Laat M. How do online learning networks emerge? A review study of selforganizing network effects in the field of Networked learning. Educ Sci 2019;9:289. 